\title{
Twentieth Century Dogmas Prevent Sustainable Healthcare
}

\author{
Rodney R Dietert ${ }^{1 *}$ and Janice M Dietert ${ }^{2}$ \\ ${ }^{1}$ Department of Microbiology and Immunology, Cornell University, Ithaca, NY 14853 USA \\ ${ }^{2}$ Performance Plus Consulting, Hereford, AZ USA \\ *Corresponding author: Rodney R Dietert, Professor Emeritus of Immunotoxicology, Cornell University, USA. \\ To Cite This Article: Rodney R Dietert, Janice M Dietert. Twentieth Century Dogmas Prevent Sustainable Healthcare. Am J Biomed Sci \& Res. \\ 2021 - 13(4). AJBSR.MS.ID.001890. DOI: 10.34297/AJBSR.2021.13.001890.
}

Received: 䟧 July 06, 2021; Published: 㘹 July 16, 2021

\begin{abstract}
One of the major impediments to sustainable healthcare is a rigid adherence to several outdated twentieth century scientific dogmas. At the center of these pre-microbiome dogmas is the mischaracterization of humans by much of the healthcare industry. We have been and, in many cases continue to be, viewed as a single species rather than a microbiome-driven, multi-species superorganism containing trillions of microbial co-partners. This prior and ongoing misunderstanding of the basic biology of humans across broad sectors of medicine, the healthcare industry, public health and governmental officials and some patients resulted in errors. These errors were not only in delivered healthcare but also in safety evaluations to protect human health (i.e., food, drug, and environmental chemical safety assessment which did not take inconsideration the microbiome). The continued pursuit of preventative and therapeutic medicine using the single-species fallacy (and ignoring the fact that we a majority microbial by both genes and cells) has ramifications. It spurs on the epidemic of noncommunicable diseases and conditions (NCDs) as well as the loss of human microbiota needed for colonization resistance against pathobionts. This opinion paper:
\end{abstract}

a) Describes the scientific evidence that repudiates seven outdated scientific dogmas.

b) Explains why these archaic dogmas should no longer drive healthcare and

c) Indicates why they must be discarded for real gains to be made in the sustainability of healthcare. Additionally, two last-century erroneous assumptions are discussed.

These old-school scientific assumptions about the relationship between immune dysfunction and human disease affect when and how regulated safety assessment for the immune system (Immunotoxicity Testing) would be performed. These two assumptions need to be reversed and more relevant and timely immunotoxicity assessment needs to be required by regulatory agencies to protect the human superorganism.

Keywords: Scientific dogmas, Human superorganism, Holobiont, Pathobiont, Microbiome, Safety assessment, Inflammation-mediated damage, Microbiota-immune co-maturation, Sustainable healthcare, Human disease convergence

Abbreviations: NCDs: Noncommunicable diseases and conditions; WHO: World Health Organization; FDA: Food and Drug Administration, NHS: National Health Service; CDC: Centers for Disease Control and Prevention; NIH: National Institutes of Health; USDA: United States Department of Agriculture

\section{Introduction}

Sustainable healthcare may be defined in several different ways depending upon one's experiences, expertise, priorities, and perspective. In 2015, we [1] proposed that a path to sustainable healthcare must first and foremost deal with the 21st century reality that humans are majority microbial by several measures. We do not exist merely as human mammals, but rather are superorganisms (or holobionts) composed of thousands of different microbial species. Human superorganism health is only possible when those thousands of different species are nurtured and given preventative and therapeutic healthcare designed for the superorganism patient. Until and unless healthcare fully embraces the 21-century reality of the human superorganism, no amount of "greening" of medical facilities (e.g., reduction in plastics) and practices or envisioned transhuman manipulations (the transplantation of nanomaterials, 
metals, and electronics into the body) will matter; healthcare will never become "sustainable." Microbiome degradation is the surest path to

1. Ever-increasing levels of human disease, and

2. Plummeting resiliency in humans. Humans as superoganisms are interconnected to non-human microbiomes in soil, air, water, plants, and animals [2]. As these are equally degraded, it will lead to the destruction of life on earth.

This opinion article details the scientific dogmas that emerged during the mid-latter part of the twentieth century that are no longer scientifically correct but, nevertheless, continue to drive most of prevailing medicine and healthcare. Archaic twentieth century dogmas need to disappear completely and be replaced by new dogmas spawning healthcare approaches that focus on the actual patient, the human superorganism. An early, partial version of the now archaic 20 th century dogmas was orally described during a January 2019 invited lecture in the Emerging Sciences Series of the National Academy of Sciences (NAS) in Washington, DC [3]. Table 1 contains the first complete, published version of the disappearing dogmas. When considered in combination, these outdated dogmas ushered in the failed healthcare approaches that generated both our current epidemic of non-communicable diseases and conditions (NCDs) as well as our loss of colonization resistance and increased vulnerability to infectious diseases/pandemics.

In addition, the current paper includes a discussion of two erroneous regulatory assumptions based on 20th century science that concerned safety testing for the immune system for exposure to food, food additives, drugs, and environmental chemicals.

In hindsight, these safety assessment assumptions resulted in two problems:

1. Under testing for immune safety, and

2. Measurement of biomarkers that were largely irrelevant as indicators of immune-inflammation-driven human disease. The lack of required screening for disease-relevant immunotoxicity hampered the overall risk-benefit analysis of xenobiotics [4].

\section{Disappearing Dogmas}

Seven, twentieth century dogmas are shown in Table1. These now-archaic dogmas are significant in that they describe various aspects of fundamental biology, safety, and human disease that impact how we pursue healthcare and protect humans from hazards. These include:

A. human immune development,

B. germ theory and how we interact with microbes,

C. the control of speciation,

D. the prime directive for safety testing of drugs, food, food additives, and environmental chemicals,

E. the partitioning of human diseases into different categories,

F. the vulnerability of humans in nature, and

G. standards to ensure that food is safe for human consumption. Importantly, these seven scientific dogmas were widely accepted and taught during the latter part of the twentieth century and continue to be a driving force in human medicine and healthcare. However, the last-century science behind these seven dogmas has been proven to be incorrect as detailed in Table 1.

Table 1: Twentieth Century Outdated Dogmas That Impede Sustainable Healthcare

\begin{tabular}{|c|c|c|c|}
\hline $20^{\text {th }}$ Century Dogma & New 21st Century Understanding & Adverse Outcome(s) of Dogma Adherence & Key References \\
\hline $\begin{array}{l}\text { 1. The newborn is fully } \\
\text { prepared immunologically } \\
\text { to fight all diseases. }\end{array}$ & $\begin{array}{l}\text { The newborn immune system must postnatally } \\
\text { co-mature with the microbiome to be } \\
\text { immunologically balanced and fully prepared } \\
\text { to fight diseases. When this fails to happen, } \\
\text { infectious, autoimmune, inflammatory, and } \\
\text { allergic diseases are more likely to occur } \\
\text { beginning in childhood and extending } \\
\text { throughout the lifespan. }\end{array}$ & $\begin{array}{l}\text { By failing to recognize the inherent immune } \\
\text { functional incompleteness of the newborn and } \\
\text { to facilitate co-maturation of human microbiota } \\
\text { and the infant immune system, immune } \\
\text { imbalances and immune dysfunctions were } \\
\text { allowed to become established in the child and } \\
\text { to persist across the lifespan. }\end{array}$ & {$[23-30]$} \\
\hline $\begin{array}{l}\text { 2. Barriers defining } \\
\text { species are driven by } \\
\text { host chromosomal genes } \\
\text { (hybrids lethal or sterile). }\end{array}$ & $\begin{array}{l}\text { Immune-microbiome incompatibility can } \\
\text { also determine species barriers (antibiotic } \\
\text { destruction of the microbiome can remove } \\
\text { some species barriers). This highlights the } \\
\text { almost sacred biological bond that has existed } \\
\text { for millennia between the immune system and } \\
\text { friendly microbiota. They are inseparable from } \\
\text { both an evolutionary and a systems biology } \\
\text { perspective. }\end{array}$ & $\begin{array}{l}\text { By failing to recognize the integral connection } \\
\text { between microbiota and the immune system } \\
\text { at the level of organismal integrity, we failed } \\
\text { to realize that immune protection of self } \\
\text { requires a high level of microbiota-immune } \\
\text { compatibility, and that immune inflammation- } \\
\text { driven self-damage of tissues and organs is } \\
\text { a default outcome of microbiome-immune } \\
\text { problems. }\end{array}$ & [34-39] \\
\hline
\end{tabular}




\begin{tabular}{|c|c|c|c|}
\hline $\begin{array}{l}\text { 3. Most microbes are a } \\
\text { threat to human health. }\end{array}$ & $\begin{array}{l}\text { Many microbes are required for human health. } \\
\text { Essential functions include: i) colonization } \\
\text { resistance; ii) production of vitamins and } \\
\text { neurochemicals; iii) metabolism of food, } \\
\text { chemicals, drugs, and bile acids; iv) maintenance } \\
\text { of epithelial barrier function; v) immune system } \\
\text { balancing and regulation. }\end{array}$ & $\begin{array}{l}\text { Achieving a mind-set necessary to preserve } \\
\text { and protect the human microbiome rather than } \\
\text { over-sanitizing our microbiota into oblivion } \\
\text { and destroying them with other anti-microbial } \\
\text { drugs, chemicals, and food additives remains } \\
\text { an ongoing challenge. }\end{array}$ & [47-53] \\
\hline $\begin{array}{l}\text { 4. The human mammal is } \\
\text { the target of environmental } \\
\text { health risk assessments } \\
\text { (e.g., toxicological safety). }\end{array}$ & $\begin{array}{l}\text { The human superorganism is the most relevant } \\
\text { target for assessment/evaluation/safety } \\
\text { determinations. Because microbes occupy } \\
\text { the routes of exposure, if the microbiome is } \\
\text { not included in environmental health risk } \\
\text { determinations, the likely internal dose and } \\
\text { potential for clinical pathology and disease is not } \\
\text { actually known. }\end{array}$ & $\begin{array}{l}\text { Because of the large percentage of existing } \\
\text { drugs, chemicals and food additives that } \\
\text { damage the human and other microbiomes, } \\
\text { we need to re-evaluate safety and use of } \\
\text { many common products for the human } \\
\text { superorganism and ensure that any future } \\
\text { products are microbiome-safe. }\end{array}$ & [55-62] \\
\hline $\begin{array}{l}\text { 5. Noncommunicable } \\
\text { diseases (NCDs) } \\
\text { are completely } \\
\text { noncommunicable. }\end{array}$ & $\begin{array}{l}\text { Specific microbe transfer appears to promote } \\
\text { certain NCDs. Such transfer is more likely when } \\
\text { recipient microbiomes have been degraded (e.g., } \\
\text { reduced colonization resistance). }\end{array}$ & $\begin{array}{l}\text { Key pathobionts are now recognized to be } \\
\text { capable of inducing specific NCDs when } \\
\text { not restricted by a robust microbiome. The } \\
\text { failure to recognize the interconnectivity of } \\
\text { communicable and noncommunicable diseases } \\
\text { and the importance of blocking pathobiont } \\
\text { carriage, via colonization resistance has led us } \\
\text { to mismanage many NCDs and to prevent the } \\
\text { emergence of additional co-morbid NCDs }\end{array}$ & [63-67] \\
\hline $\begin{array}{l}\text { 6. Humans are poorly } \\
\text { suited to exist in } \\
\text { earth's “dangerous" } \\
\text { natural environment } \\
\text { and require significant } \\
\text { intervention with } \\
\text { antibiotics/antimicrobials, } \\
\text { polypharmacy, vaccines, } \\
\text { sunscreens, sanitizing } \\
\text { agents, separation/ } \\
\text { isolation, and even } \\
\text { transhuman technology } \\
\text { (e.g., nanomaterials). }\end{array}$ & $\begin{array}{l}\text { Humans are perfectly suited to live in earth's } \\
\text { environments when existing as fully formed } \\
\text { superorganisms (holobionts) that reflect a } \\
\text { composite of life on earth. }\end{array}$ & $\begin{array}{l}\text { The reality is that humans are superorganisms } \\
\text { whose microbial copartners have relatives } \\
\text { in every part of earth. Many medical/public } \\
\text { health interventions, to date, have weakened us } \\
\text { as superorganisms, made us less complete, and } \\
\text { reduced our resiliency. The prime directive of } \\
\text { sustainable healthcare should be to support us } \\
\text { as superorganisms. }\end{array}$ & [70-80] \\
\hline $\begin{array}{l}\text { 7. Food products that } \\
\text { receive US FDA and/ } \\
\text { or USDA approval are } \\
\text { generally assumed to be } \\
\text { safe and as a result, not } \\
\text { likely to compromise one's } \\
\text { health. }\end{array}$ & $\begin{array}{l}\text { The majority of food in major grocery stores } \\
\text { contains main components (sugar, hidden } \\
\text { phytoestrogens), food additives (e.g., emulsifiers, } \\
\text { artificial sweeteners) and/or contaminants } \\
\text { (e.g., glyphosate) that readily damage health. } \\
\text { This occurs either through direct damage to the } \\
\text { microbiome or after the transfer of metabolites } \\
\text { across the gut barrier. Yet, consumers are not } \\
\text { alerted to the dangers that major food products } \\
\text { present. As currently designed, they feed } \\
\text { dysfunction and disease. }\end{array}$ & $\begin{array}{l}\text { The most readily available foods in many } \\
\text { westernized countries feature main ingredients } \\
\text { that are obesogenic and additives that can } \\
\text { severely damage the gut microbiome and } \\
\text { compromise the gut barrier. A food revolution } \\
\text { is needed (e.g., regenerative agriculture) that } \\
\text { fundamentally sustains planetary microbiomes } \\
\text { and nurtures rather than destroys the human } \\
\text { superorganism. }\end{array}$ & [84-92] \\
\hline
\end{tabular}

Much of the new data and scientific evidence resulting in new dogmas stems from the explosion of research into the microbiome [5], and the recognition that the microbiome plays a huge role in determining human [6-9], as well as animal [10-14] and plant health [15-17]. Earth is fundamentally a microbial planet [18,19], and most complex organisms on earth have microbiome co-partners that contribute to a spaceship earth concept in which the interlinked microbiome contributes to health vs. disease $[20,21]$. Ironically, some sectors of agriculture and earth's ecological management have been completely ready to discard archaic dogmas and fully embrace the chicken superorganism [12] and soil-plant [13] microbiomes as being the most critical features of health management. One Health refers to the combination of knowledge that flows between and supports human medicine and veterinary medicine. The veterinary medicine component of One Health seems to be willing to discard the archaic and false dogma that their patients are single species [22].

Only within human medicine, healthcare, and the associated industries and governmental regulatory bodies is there a stubborn reluctance to move into the $21^{\text {st }}$ century when it comes to basic human biology. As humans, we brought forward the microbiome revolution, but as human superorganism patients, we seem to be the last to directly benefit from it. It may be time to ask why we do not see more benefit from the microbiome revolution and to insist that we as human superorganisms are not left behind our pets, 
wildlife, and food-producing animals in receiving the latest sciencedriven health benefits.

\section{Dogma\#1}

The first archaic dogma that still affects human healthcare is the idea that babies are born with immune systems that are peripherally distributed and balanced across the newborn's tissues, that mucosal immunity is fully in place, and that the baby's immune system is fully ready to withstand all pathobiont challenges and to greet all vaccinations with ringing success. As shown in Table 1 Dogma 1, this assumption could not be further from the truth [23-30]. The baby's immune system has been selectively suppressed during in utero development, and the baby emerges from the womb with an immune system that is incomplete, unbalanced, misregulated as per inflammation and programmed more for future disease than future health. The infant immune system must co-mature with the newly installed and fed microbiome [31]. Only when and after this happens is the baby's immune system truly ready to go. Disruption of the seeding, colonization, and feeding of the newborn's microbiota (e.g., mode of delivery, antibiotic treatments, formula feeding) without appropriate microbiota remediation is a major problem for future health [32].

\section{Dogma \#2}

Recent research into the immune-microbiome connection (Table 1, Dogma 2) has two major implications. It not only establishes that the bond between the immune system and the microbiome is biologically sacred, it also changes much of how we view the origins of species. During the 20th century the concepts of species evolution, including natural selection for chromosomallyinherited species separation as advocated by Charles Darwin, were increasingly accepted and touted. In contrast, the different theories of Jean-Baptiste Lamarck who advocated for environmental adaptation were gradually discredited [33]. The restoration of Lamark's ideas began once the importance of transgenerational epigenetics and inherited environmental adaptation was recognized. According to strict Dawinian theory, rigidly fixed chromosomal gene incompatibilities that separate species result in hybrid lethality and/or sterility. But a major exception has been found through the work of Seth Bordenstein (Vanderbilt University) and others that shatters the strict Darwinian view of how species are separated and how that separation is maintained.

In some species, when an immune system is presented with a microbiome that was never encountered by prior generations, the immune system can react against the "foreign" microbiome and attack it. This can result in hybrid lethality in the offspring caused by a massive inflammatory response. In effect, the immunemicrobiome dysbiosis inhibits successful reproduction and as a result, produces a new species. But this is not a rigid species separation as Darwin might have envisioned. Instead, it is "flexible" and environmentally adaptable in line with Lamark's theories. For example, when species that are separated by immune-microbiome incompatibilities are treated with antibiotics (essentially eliminating the immune-offending microbiome), the species barrier goes away. The formerly different species are at least temporarily members of the "same tribe." Any lingering doubt concerning the importance of immune-microbiome interactions should be eliminated by these new scientific findings. The new scientific $21 \mathrm{st}$ century scientific dogma is:

1. That the superorganism (also called the holobiont) may well be the significant evolutionary unit and,

2. That immune-microbiome status can determine whether a new species exists or not [34-39].

It is worth considering that immune-microbiome dysbiosis resulting in immune-inflammation-inflicted NCDs may simply be a milder version of self-rejection (immune-microbiome incompatibility) than occurs via hybrid lethality across a species barrier. The key take-home lesson for healthcare from this new science is for good health and appropriately regulated inflammation, it is necessary to keep the immune system and the microbiome operating in sync.

\section{Dogma \#3}

One of the dogmas of the 20th century that has been a challenge to overcome is the idea that the only good microbe is a dead microbe. The long history of incarnations of the germ theory of disease became paired with new tools: an arsenal of antibiotics. The result was what became an indiscriminate killing spree against bacteria. The ability to cure previously untreatable bacterial infections quickly turned into antibiotic overuse and an epidemic of NCDs $[40,41]$.

The $20^{\text {th }}$ century mantra of kill all microbes that still shows up in overuse of antibiotics as well as sanitizers/cleaning agents ignores three facts.

1. Elie Metchnikoff was an early 20th century Nobel Prizewinning immunologist. His contribution to science and medicine was in discovering macrophages and their functional capacity to phagocytize (engulf) and then kill bacteria. What is less well known is that Meticknikoff did not believe that all bacteria should be engulfed and killed. Quite the contrary. He was an early proponent of probiotics. Metchinkoff believed that consumption of probiotics led to a longer, healthier life [42].

2. Alexander Fleming was the discoverer of penicillin. His discovery led to the antibiotic revolution of the 20th century. Given the era in which Fleming worked and the importance of his discovery in saving lives, one might assume that Fleming was 
a proponent of the mantra that "the only good microbe is a dead microbe." But this was not the case. Alexander Fleming loved microbes and was a pioneer in creating art using pigmented bacteria and fungi $[43,44]$.

3. The reality is that we as human superorganisms are by several measures mainly microbial [45]. The killing of bacteria by antibiotics beyond the specific target pathobiont is, in reality, the destruction of a necessary part of our body. It has been a challenge for healthcare to place the human microbiomes in the category of vital organs [46]. But 21st century science indicates that is precisely the role played by our various microbiomes (gut, skin, airways, urogenital tract, breast tissue and breast milk). Table 1, Dogma 3 illustrates the vital role played by our friendly microbes, which includes not only regulation of the immune system and control of neurochemical, hormonal, and metabolic functions, but also the front-line defense of colonization resistance against pathogens [47-53]. Ironically when our friendly microbes are killed, we are at greater risk of infections [54] as well as NCDs.

\section{Dogma \#4}

In an era in which the medical priority was to sanitize humans of any and all microbes, protection of human microbiota was viewed as not only illogical but also potentially harmful for human health. As the result and as described in Dietert and Silbergeld [55] one of the driving forces in standardizing 20th century human health protection (the U.S. National Research Council's 1987 model for environmental expos health risk assessment) completely excluded the microbiome.

In the 21 century's era of the microbiome, this is a particularly egregious omission, because the human microbiome occupies what are known toxicologically as the routes of human exposures (the skin for dermal exposures, the airways for inhalation exposure, the gastrointestinal tract for oral exposures, the urogenital tract for urogenital exposure). Additionally, the human microbiome has massive metabolic activity. As a result, it is not surprising that the microbiome exerts a major influence over precisely what chemicals in what concentrations are delivered across barriers to our mammalian cells. The microbiome affects the internal exposure dose to potential toxicants (and ultimately the exposome over the life course). The critical role of the microbiome in environmental health risk assessment for human health protection has made National Research Council's prior 1987 model (and a continuing guide) increasing irrelevant [55].

Table 1, Dogma 4 points out that continuing into the 21st century, regulated safety testing has remained focused on the singlespecies human mammal rather than the human superorganism. Furthermore, the legacy of failure to identify prior risk to the human microbiome, as drugs, food, food additives and environmental chemicals were approved for use, means that countless drugs, food and food additives, and environmental chemicals are utilized that are toxic for human commensal microbiota. It means that we must think well beyond just antibiotics for products that damage/ destroy the human microbiome and promote both .communicable diseases and NCDs [55-62].

\section{Dogma \#5}

One of the major 20th century dogmas (Table1, Dogma 5) regarding human disease is that all diseases may be divided into two distinct categories: communicable (infectious) diseases and noncommunicable (or non-infectious) diseases and conditions. In a stunning reversal of the way of categorizing disease, the boundary between communicable and noncommunicable diseases has been shown to be soft rather than hard and, quite possibly, non-existent [63-67]. This means that while the ever-expanding number of medically-coded NCDs (driven by expansion in the number of autoimmune diseases and conditions) is contracting when it comes to cause/core underlying dysfunction (i.e., misregulated inflammation) [68,69], there is a convergence between communicable and noncommunicable disease categories [6367]. The reality is that human disease is not as overwhelming and complex as previously thought. This raises serious questions as to whether we really need the ever-expanding plethora of prescription drugs and complex treatment protocols or if simpler core cures eliminating multiple disease conditions are within reach? That would be a significant step toward sustainable healthcare.

\section{Dogma \#6}

One of the gross misrepresentations of microbiome-immune dysbiosis and the loss of resiliency (via loss of colonization resistance) is the recent public health supposition that humans are ill-suited for life within earth's environments. This is Dogma \#6 in Table 1 [70-80]. We are constantly told that we have to be protected from Earth, its dangerous microbes, and its unhealthy environments. The reality is that we should be immersed in that which makes us complete and strong as superorganisms. We need more microbes not fewer. We need more exposure to soil and farmassociated microbes [81-83]. The suggestions that we should fear microbes and pursue more medical care, more drugs (increased polypharmacy), more protective gear, an increasingly sanitized living environment, and less human-human contact would only further damage our microbiomes and make us increasingly immunologically compromised as an outcome. This dogma must be rejected if we are ever to pursue sustainable healthcare. Transhumanism is only the illusion of health. Instead, the solutions are within earth, its microbial life, and its environments and in the human-human, human-animal, and human-nature contacts that helped our indigenous peoples/ancestors to thrive. 


\section{Dogma \# 7}

Breastmilk is considered the gold standard of baby food. Human milk was designed across millennia by nature to feed, first and foremost, the baby's microbiota rather than the human mammal. Given this, we need to rethink our food. Is our food safe and supportive of our microbiomes from cradle to grave? Table 1, Dogma 7 concerns the 20th century-idea that government approved food is safe for human consumption. This dogma needs to be rejected for the sake of human health. The reality is that the most readily available food on grocery store shelves is not safe for the human superorganism [84-92]. It is loaded with microbiome destroying sugar (e.g., sucrose), artificial sweeteners, high fat, and food emulsifiers. The latter category of food additives by itself can destroy the mucin-protecting bacteria of the gut, compromise the gut lining, and promote metabolic syndrome [93]. There are many risk factors contributing to the obesity epidemic, but food emulsifiers are sufficient to place our children on the obesity path and to prevent adults from avoiding the many obesity-related, comorbid NCDs. Yet, they remain in most of our food despite their known toxicity for bacteria that are absolutely required for a healthy gut (Akkermansia muciniphila). The lack of safety for the human microbiome and the underlying immune system among the most prevalent foods is a significant problem. Of course, food safety is regulated by federal agencies such as the U.S. Food and Drug Administration and the U.S. Department of Agriculture.

\section{Erroneous Assumptions Regarding Immune Safety Assessment}

While much of the 20th century legacy resulting in disease concerned the microbiome, there were, also, issues pertaining directly to the immune system and its protection from food, drug, and environmental chemical hazards. Two major issues arose during the last two decades of the 20th century that persist even now. One concerns when immune safety testing will be required by regulatory agencies, and the second is what specific immunotoxicity testing would be requested.

Remarkably, immunotoxicity testing has not been automatically required by agencies such as the U.S. FDA [94]. Instead, immuntoxicity testing has to be triggered in a second tier level of screening. To require immuntoxicity testing there has to be sufficient "cause for concern." There has to be an immune red flag within the results from the 1st Tier level of screening. Tier 1 includes screening for histopathology, reproductive and/ or general developmental toxicity as a priority over immune functional assessment. Tier 1 screening is performed using an unchallenged immune system. The immune system was not asked to mount any type of response. Hence, the chance of actually seeing immune red flags in Tier 1 screening is significantly diminished. The reality is that S8 Tier 1 toxicity screening lacks direct immuntoxicity testing and, in particular, the lack of functional immune assessment is problematic.

The FDA problem is that we now know the type(s) of immunotoxicity that contribute to much of human disease. The disease-promoting types of immune dysfunction are unlikely to be detected in the general required tests (e.g., they need pathobiont challenge to show up). Hence, required/regulated immunotoxicity testing would rarely be triggered even though immune dysfunction leading to misregulated inflammation (the greatest contributor to the world's greatest killer, NCDs) might exist. The take home message is that this tiered system that lacks up front immunotoxicity testing produces a predictable outcome: an arguably inadequate level of required immunotoxity testing.

A second problem concerns the default testing protocols when immunotoxicity testing is required. There is a significant reliance on one functional immune test: the T-dependent antibody response or TDAR [95]. In this case, the TDAR (which came into favor during the HIV-AIDS era) is designed to detect suppressed antibody production as opposed to elevated or inappropriate antibody production as might occur with allergic or autoimmune diseases. Of course, the immune biomarkers that are associated with today's most prevalent life-threatening diseases are connected to inappropriate inflammatory responses [69]. One example of these would be: the cytokine storm, an immune response problem experienced as a serious complication of Covid-19 infection [96]. Note that immunotoxicity testing can be performed that would detect inflammation-based problems arising during a pathobiont challenge. An example would be host resistance-immune assays in lab animals using influenza challenge [97]. However, while highly relevant to current day concerns and permitted under second tier analyses by the U.S. FDA, these types of immune functional analyses during pathobiont challenge in mucosal tissues have not been routinely required in regulated safety assessment.

As a result, the mystifying relegation of immune health risk assessment to an evaluation of secondary importance and the predominant use of non-disease-relevant functional biomarkers (i.e., TDAR) when the assessment was required does little to flag potential immunotoxic risk factors contributing to metabolic syndrome, cardiovascular disease, or cancer. We can and should do better to ensure that when toxicological assessment is required to be performed, it has relevance to the dysfunction that promotes human disease. Our knowledge of commonalities among NCDs should drive a revolution in regulated safety testing that focuses first on the microbiome and immune interconnection in mucosal tissues (e.g., the microimmunosome) 


\section{Conclusions}

Sustainable healthcare can be within reach. But the regulatory, medical, pharmaceutical, healthcare, and public health communities must be willing to:

a) Reject outdated scientific dogmas,

b) Embrace the human superorgansim as both the patient and the target for environmental protection, and

c) Fully implement prime directive policies that protect human microbiomes and the human immune system. They must be willing to protect the microbiome and immune system and to first and foremost correct dysbiosis in the microimmunosome.

The end result of such changes by these communities is that there would be a reduction in healthcare needs. Those communities could shrink in size and influence because there would be a reduced demand for pharmaceuticals, doctor visits, and hospital visits. The potential future impact of disease-empowered organizations (e.g., World Health Organization, Centers for Disease Control and Prevention, CDC, National Institutes for Health, National Health Service, UK, and the U.S. Food and Drug Administration) would be reduced. Are we willing to accept that?

Such change in thinking and operations is a critical part of achieving sustainable healthcare.

There are ample reasons to soundly reject the current healthcare system and its status quo. It features:

1. An ever-expanding number of medically-coded human diseases,

2. Increasing numbers of new drugs specific for each disease,

3. Increasing treatment protocols specific for each new disease,

4. Increasing prevalence of co-morbid NCDs, and

5. Increasing human vulnerability to infectious diseases/ pandemics.

Of course, we now know that these negative outcomes for human health are based, at least in part, on current preventative and therapeutic medical treatments, regulatorily-approved environmental chemical use, and the predominant foods on grocery store shelves that all contribute to the destruction of the human microbiome. Combined, this healthcare/health protection system has increased human disease, increased medical needs, increased human suffering, and reduced human quality of life. As humans, we are superorganisms and a reflection of all life on earth. The healthcare system needs to treat us as such.

\section{Acknowledgements}

The authors thanks Peg Coleman, Colman Consulting, for her helpful discussion in microbiology and risk analysis.

\section{Conflict of Interest}

The authors declare that there is no conflict of interest.

\section{References}

1. Dietert RR, Dietert JM (2015) The Microbiome and Sustainable Healthcare. Healthcare (Basel) 3(1): 100-129.

2. Ma B, Wang Y, Ye S, Liu S, Stirling E, et al. (2020) Earth microbial co-occurrence network reveals interconnection pattern across microbiomes. Microbiome 8(1): 82.

3. Rodney Dietert (2019) "The Microbiome and Immune System in Environmental Risk of Infectious Disease". USA.

4. Dietert RR, Luebke RW (eds.) (2012) Immunotoxicity, Immune Dysfunction and Chronic Disease. Humana/Springer. pp.468.

5. NIH Human Microbiome Portfolio Analysis Team (2019) A review of 10 years of human microbiome research activities at the US National Institutes of Health, Fiscal Years 2007-2016. Microbiome 7: 31

6. Santacroce L, Man A, Charitos IA, Haxhirexha K, Topi S, et al. (2021) Current knowledge about the connection between health status and gut microbiota from birth to elderly. A narrative review. Front Biosci (Landmark Ed) 26(6): 135-148.

7. Visconti A, Le Roy CI, Rosa F, Rossi N, Martin TC, et al. (2019) Interplay between the human gut microbiome and host metabolism. Nature Communications 10(1): 4505.

8. Badal VD, Wright D, Katsis Y, Kim H-C, Swafford AD, et al. (2019) Challenges in the construction of knowledge bases for human microbiome-disease associations. Microbiome 7(1): 129.

9. Zheng D, Liwinski T, Elinav E (2020) Interaction between microbiota and immunity in health and disease. Cell Res 30(6): 492-506.

10. Ramírez GA, Richardson E, Clark J, Keshri J, Drechsler Y, et al. (2020) Broiler chickens and early life programming: Microbiome transplantinduced cecal community dynamics and phenotypic effects. PLOS One 15(11): e0242108.

11. Khan S, Moore RJ, Stanley D, Chousalkar KK (2020) The Gut Microbiota of Laying Hens and Its Manipulation with Prebiotics and Probiotics to Enhance Gut Health and Food Safety. Appl Environ Microbiol 86(13): e00600-e00620.

12. Maki JJ, Klima CL, Sylte MJ, Looft T (2019) The Microbial Pecking Order: Utilization of Intestinal Microbiota for Poultry Health. Microorganisms $7(10): 376$.

13. Xu H, Huang W, Hou Q, Kwok LY, Laga W, et al. (2019) Oral Administration of Compound Probiotics Improved Canine Feed Intake, Weight Gain, Immunity and Intestinal Microbiota. Front Immunol 10: 666.

14. Gibson KM, Nguyen BN, Neumann LM, Miller M, Buss P, et al. (2019) Gut microbiome differences between wild and captive black rhinoceros implications for rhino health. Sci Rep 9(1): 7570.

15. Mercado-Blanco J, Abrantes I, Barra Caracciolo A, Bevivino A, Ciancilo A, et al. (2018) Belowground Microbiota and the Health of Tree Crops. Front Microbiol 9: 1006.

16. Pang Z, Chen J, Wang T, Guo C, Li Z, et al. (2021) Linking Plant Secondary Metabolites and Plant Microbiomes: A Review. Frontiers Plant Science 12: 621276

17. Gupta R, Anand G, Gaur R, Yadav D (2021) Plant-microbiome interactions for sustainable agriculture: a review. Physiol Mol Biol Plants 27(1): 165179. 
18. Onstott TC, Ehlmann BL, Sapers H, Coleman M, Ivarsson M, et al. (2019) Paleo-Rock-Hosted Life on Earth and the Search on Mars: A Review and Strategy for Exploration. Astrobiology 19(10): 1230-1262.

19. Timmis K, Ramos JL (2021) The soil crisis: the need to treat as a global health problem and the pivotal role of microbes in prophylaxis and therapy. Microbial Biotechnology 14(3): 769-797.

20. Sehnal L, Brammer-Robbins E, Wormington AM, Blaha L, Bisesi J, et al. (2021) Microbiome Composition and Function in Aquatic Vertebrates Small Organisms Making Big Impacts on Aquatic Animal Health. Frontiers in Microbiology 12: 567408.

21. Prescott SL, Bland JS (2020) Spaceship Earth Revisited: The Co-Benefits of Overcoming Biological Extinction of Experience at the Level of Person, Place and Planet. Int J Environ Res Public Health 17(4): 1407

22. Pilla R, Suchodolski JS (2020) The Role of the Canine Gut Microbiome and Metabolome in Health and Gastrointestinal Disease. Front Vet Sci 6: 498.

23. Angelone DF, Wessels MR, Coughlin M, Suter EE, Valentini P, et al. (2006) Innate immunity of the human newborn is polarized toward a high ratio of IL-6/TNF- $\alpha$ production in vitro and in vivo. Pediatric Research $60(2)$ : 205-209.

24. Zaghouani H, Hoeman CM, Adkins B (2009) Neonatal immunity: faulty T-helpers and the shortcomings of dendritic cells. Trends in Immunology 30(12): 585-591.

25. Gensollen T, Iyer SS, Kasper DL, Blumberg RS (2016) How colonization by microbiota in early life shapes the immune system. Science 352(6285): 539-544.

26. Jenmalm MC, Prescott SL (2017) The intestinal microbiota and the child's immune system. Chapter 6 in: Brown, et al. (edn.) Microbiota in Health and Disease: from Pregnancy to Childhood. Waganin Academic Publishers.

27. Zhang X, Zhivaki D, Lo-Man R (2017) Unique aspects of the perinatal immune system. Nat Rev Immunol 17(8): 495-507.

28. Uebelhoer LS, Lancioni CL (2018) CD4+ T Cell Activation During the Newborn Period: Barriers Against and Pathways Toward Th1 Immunity. Crit Rev Immunol 38(1): 1-15.

29. Renz H, Adkins BD, Bartfeld S, Blumberg RS, Farber DL, et al. (2018) The neonatal window of opportunity-early priming for life. J Allergy Clin Immunol 141(4): 1212-1214.

30. Yu JC, Khodadadi H, Malik A, Davidson B, E da Silva Lopez Salle et al. (2018) Innate Immunity of Neonates and Infants. Front Immunol 9: 1759.

31. Henrick BM, Rodriguez L, Lakshmikanth T, Pou C, Henckel E, et al. (2021) Bifidobacteria-mediated immune system imprinting early in life. Cell 15 S0092-8674(21)00660-7.

32. Renz H, Skevaki C (2021) Early life microbial exposures and allergy risks: opportunities for prevention. Nat Rev Immunol 21(3): 177-191.

33. Steele EJ, Gorczynski RM, Lindley RA, Liu Y, Temple R, et al. (2019) Lamarck and Panspermia - On the Efficient Spread of Living Systems Throughout the Cosmos. Progress Biophyics and Molecular Biology 149: 10-32.

34. Brucker RM, Bordenstein SR (2013) The hologenomic basis of speciation: gut bacteria cause hybrid lethality in the genus Nasonia. Science 341(6146): 667-669.

35. Wang J, Kalyan S, Steck N, Turner, Harr B, et al. (2015) Analysis of intestinal microbiota in hybrid house mice reveals evolutionary divergence in avertebrate hologenome. Nature Communications 6(1): 1-10.

36. Shropshire JD, Bordenstein SR (2016) Speciation by Symbiosis: The Microbiome and Behavior. mBio 7(2): e01785.
37. Sevellec M, Derome N, Bernatchez L (2018) Holobionts and ecological speciation: the intestinal microbiota of lake whitefish species pairs. Microbiome 6: 47.

38. Lim S J, Bordenstein SR (2020) An introduction to phylosymbiosis. Proc Biol Sci 287(1922): 20192900.

39. Cross KL, Leigh BA, Hatmaker EA, Mikaelyan A, Miller AK, et al (2021) Genomes of Gut Bacteria from Nasonia Wasps Shed Light on Phylosymbiosis and Microbe-Assisted Hybrid Breakdown. mSystems (2): e01342-20.

40. Blaser MJ (2014) Missing Microbes: How the Overuse of Antibiotics Is Fueling Our Modern Plagues Henry Holt and Co. pp. 288.

41. World Health Organization (2021) Noncommunicable Diseases.

42. Podolsky SH (2012) Metchnikoff and the microbiome. Lancet 380(9856): 1810-1811.

43. Madhusoodanan J (2016) Science and Culture: Petri palettes create microbial masterpieces. Proc Natl Acad Sci U S A. 113(40):11056-11058.

44. Dunn R (2010) Painting with Penicillin: Alexander Fleming's Germ Art Smithsonian Magazine.

45. Qin J, Li R, Raes J, Arumugam M, Burgdorf KS, et al. (2010) A human gut microbial gene catalogue established by metagenomic sequencing. Nature 464: 59-65.

46. Dietert RR (2014) The microbiome in early life: self-completion and microbiota protection as health priorities. Birth Defects Res B Dev Reprod Toxicol 101(4): 333-340.

47. Le Blanc JG, Milani C, De Giori GS, Sesma F, Van Sinderen D, et al. (2013) Bacteria as vitamin suppliers to their host: a gut microbiota perspective. Curr Opin in Biotechnol 24(2): 160-168.

48. Sharon G, Garg N, Debelius J, Knight R, Dorrestein PC, et al. (2014) Specialized metabolites from the microbiome in health and disease. Cell Metabolism 20(5): 719-730.

49. Dietert RR (2016) The Human Superorganism: How the Microbiome is Revolutionizing the Pursuit of a Healthy Life. Dutton Penguin Random House New York, pp. 341

50. Abuqwider JN, Mauriello G, Altamimi M (2021) Akkermansia muciniphila, a New Generation of Beneficial Microbiota in Modulating Obesity: A Systematic Review. Microorganisms (5): 1098.

51. Morar N, Bohannan B J (2019) The conceptual ecology of the human microbiome. The Quarterly Review of Biology 94(2): 149-175.

52. Dietert R (2021) Lessons for Human Holobiont Medicine in The Era of SARS-Cov-2. Amer J Biomed Sci and Res 13(2): 152-156.

53. Wu Y, Wang CZ, Wan JY, Yao H, Yuan CS, et al. (2021) Dissecting the Interplay Mechanism between Epigenetics and Gut Microbiota: Health Maintenance and Disease Prevention. Int J Mol Sci 22(13): 6933.

54. Kim S, Covington A, Pamer EG (2017) The intestinal microbiota: Antibiotics, colonization resistance, and enteric pathogens. Immunol Rev 279(1): 90-105

55. Dietert RR, Silbergeld EK (2015) Biomarkers for the 21st century: listening to the microbiome. Toxicol Sci 144(2): 208-216.

56. Dietert RR (2017) Safety and risk assessment for the human superorganism. Human and Ecological Risk Assessment 23(8): 18191829.

57. Dietert RR (2018) A Focus on Microbiome Completeness and Optimized Colonization Resistance in Neonatology. Neo Reviews 19 (2): e78-e88.

58. Mesnage R, Antoniou MN, Tsoukalas, Goulielmos GN, Tsatsakis A, et al. (2018) Gut microbiome metagenomics to understand how xenobiotics impact human health. Current Opinion in Toxicology 11: 51-58.

59. Weersma RK, Zhernakova A, Fu J (2020) Interaction between drugs and the gut microbiome. Gut 69(8): 1510-1519. 
60. Sutherland VL, Mc Queen CA, Mendrick D, Gulezian D, Cerniglia C, et al. (2020) The Gut Microbiome and Xenobiotics: Identifying Knowledge Gaps. Toxicol Sci 176(1): 1-10.

61. Zimmermann M, Patil KR, Typas A, Maier L (2021) Towards a mechanistic understanding of reciprocal drug-microbiome interactions. Mol Syst Biol 17(3): e10116.

62. Calatayud Arroyo M, García Barrera T, Callejón Leblic B, Arias Borrego A, Collado MC, et al. (2021) A review of the impact of xenobiotics from dietary sources on infant health: Early life exposures and the role of the microbiota. Environ Pollut 269: 115994.

63. Teufelberger AR, Bröker BM, Krysko DV, Bachert C, Krysko O, et al. (2019) Staphylococcus aureus Orchestrates Type 2 Airway Diseases. Trends Mol Med 25(8): 696-707.

64. Finlay BB, Humans CIFAR (2020) Are noncommunicable diseases communicable? Science 367(6475): 250-251.

65. Huang R, Ju Z, Zhou PK (2020) A gut dysbiotic microbiot-based hypothesis of human-to- human transmission of non-communicable diseases. Sci Total Environ 141030.

66. Britton GJ, Contijoch EJ, Spindler MP, Aggarwala V, Dogan B, et al. (2020) Defined microbiota transplant restores Th17/RORyt+ regulatory $\mathrm{T}$ cell balance in mice colonized with inflammatory bowel disease microbiotas. Proc Natl Acad Sci U S A 117(35): 21536-21545.

67. Baldelli V, Scaldaferri F, Putignani L, Del Chierico F (2021) The Role of Enterobacteriaceae in Gut Microbiota Dysbiosis in Inflammatory Bowel Diseases. Microorganisms 9(4): 697.

68. Dietert RR (2017) The microbiome-immune-host defense barrier complex (microimmunosome) and developmental programming of noncommunicable diseases. Reprod Toxicol 68: 49-58.

69. Furman D, Campis J, Verdin E, Carrera-Bastos P, Targ S, et al. (2019) Chronic inflammation in the etiology of disease across the life span. Nat Med 25: 1822-1832.

70. Patrick DM, Sbihi H, Dai DLY, Al Mamun A, Rasali D, et al. (2020) Decreasing antibiotic use, the gut microbiota, and asthma incidence in children: evidence from population-based and prospective cohort studies. Lancet Respir Med 8(11): 1094-1105.

71. Ni J, Friedman H, Boyd BC, Mc Gurn A, Babinski P, et al. (2019) Early antibiotic exposure and development of asthma and allergic rhinitis in childhood. BMC Pediatr 19(1): 225.

72. Scott EA, Bruning E, Nims RW, Rubino JR, Ijaz MK, et al. (2020) A $21^{\text {st }}$ century view of infection control in everyday settings: Moving from the Germ Theory of Disease to the Microbial Theory of Health. Am J Infect Control 48(11): 1387-1392.

73. Sonnenburg JL, Sonnenburg ED (2019) Vulnerability of the industrialized microbiota. Science 366(6464): eaaw9255.

74. Hallberg P, Smedje H, Eriksson N, Kohnke H, Daniilidou M, et al. (2019) Pandemrix-induced narcolepsy is associated with genes related to immunity and neuronal survival. EBio Medicine 40: 595-604.

75. Watanabe K, Umegaki H, Sugimoto T, Fujisawa C, Komiya H, et al (2021) Associations Between Polypharmacy and Gait Speed According to Cognitive Impairment Status: Cross-Sectional Study in a Japanese Memory Clinic. J Alzheimers Dis.

76. Scarlata S, Cardaci V, Santangelo C, Matarese M, Cesari, et al. (2021) Distancing Measures in COVID-19 Pandemic: Loneliness, More than Physical Isolation, Affects Health Status and Psycho-Cognitive Wellbeing in Elderly Patients with Chronic Obstructive Pulmonary Disease. COPD 28: 1-6.

77. Zheng H, Gu Z, Pan Y, Chen J, Xie Q, et al. (2021) Biotransformation of rare earth oxide nanoparticles eliciting microbiota imbalance. Part Fibre Toxicol 18(1): 17.

78. Peng Y, Zhang D, Chen T, Xia Y, Wu P, et al. (2021) Gut microbiome and resistome changes during the first wave of the COVID-19 pandemic in comparison with pre-pandemic travel-related changes. J Travel Med 5: taab067.

79. Ghafoor D, Khan Z, Khand A, Ualiyeva D, Zaman N, et al. (2021) Excessive use of disinfectants against COVID-19 posing a potential threat to living beings. Curr Res Toxicol 2: 159-168.

80. Bouslimani A, R da Silva, Kosciolek T, Janssen S, Callewaert C, et al. (2021) The impact of skin care products on skin chemistry and microbiome dynamics. BMC Biol 17: 47.

81. Smith DG, Martinelli R, Besra GS, Illarionov PA, Szatmari I, et al. (2019) Identification and characterization of a novel antiinflammatory lipid isolated from Mycobacterium vaccae, a soil-derived bacterium with immunoregulatory and stress resilience properties. Psychopharmacology (Berl) 236(5): 1653-1670.

82. Jatzlauk G, Bartel S, Heine H, Schloter M, Krauss-Etschmann S, et al (2017) Influences of environmental bacteria and their metabolites on allergies, asthma, and host microbiota. Allergy 72(12): 1859-1867.

83. Frei R, Roduit C, Ferstl R, O’Mahony L, Lauener RP, et al. (2019) Exposure of Children to Rural Lifestyle Factors Associated with Protection Against Allergies Induces an Anti-Neu5Gc Antibody Response. Front Immunol 10: 1628.

84. Delgado I, Dexpert S, Sauvant J, Cryan JF, Capuron L, et al. (2021) Influence of pro-obesogenic dietary habits on stress-induced cognitive alterations in healthy adult volunteers. Neurobiol Stress 15:100353.

85. Burr AHP, Bhattacharjee A, Hand TW (2020) Nutritional Modulation of the Microbiome and Immune Response. J Immunol 205(6):1479-1487.

86. Perazza LR, Mitchell PL, Jensen BAH, Daniel N, Boyer M, et al. (2020) Dietary sucrose induces metabolic inflammation and atherosclerotic cardiovascular diseases more than dietary fat in LDLr-/-ApoB100/100 mice. Atherosclerosis 304: 9-21.

87. Satokari R (2020) High Intake of Sugar and the Balance between Proand Anti-Inflammatory Gut Bacteria. Nutrients 12(5):1348.

88. Hu J, Lesseur C, Miao Y, Manservisi F, Panzacchi S, et al. (2021) Low-dose exposure of glyphosate-based herbicides disrupt the urine metabolome and its interaction with gut microbiota. Sci Rep11(1): 3265.

89. Bancil AS, Sandall AM, Rossi M, Chassaing B, Lindsay JO, et al. (2021) Food Additive Emulsifiers and Their Impact on Gut Microbiome, Permeability, and Inflammation: Mechanistic Insights in Inflammatory Bowel Disease. J Crohns Colitis 15(6): 1068-1079.

90. Shil A, Chichger H (2021) Artificial Sweeteners Negatively Regulate Pathogenic Characteristics of Two Model Gut Bacteria, E. coli and E. faecalis. Int J Mol Sci 22(10): 5228.

91. Sleiman HK, de Oliveira JM, Langoni de Freitas GB (2021) Isoflavones alter male and female fertility in different development windows. Biomed Pharmacother 140: 111448.

92. Mansour SR, Moustafa MAA, Saad BM, Hamed R, Moustafa AA, et al. (2021) Impact of diet on human gut microbiome and disease risk. New Microbes New Infect 41: 100845.

93. Naimi S, Viennois E, Gewirtz AT, Chassaing B (2021) Direct impact of commonly used dietary emulsifiers on human gut microbiota. Microbiome 9(1): 66.

94. US, FDA, S8 Guidance Immunotoxicity Studies for Human Pharmaceuticals (2006).

95. Herzyk DJ, Holsapple M (2007) Immunotoxicity evaluation by immune function tests: focus on the T-dependent antibody response (TDAR) [Overview of a Workshop Session at the 45th Annual Meeting of the Society of Toxicology (SOT) March 5-9, 2006, San Diego, CA]. J Immunotoxicol 4(2): 143-147.

96. Fajgenbaum DC, June CH (2020) Cytokine Storm. NEW England Journal of Medicine 383: 2255-2273.

97. Burleson GR, Burleson FG (2008) Testing human biologicals in animal host resistance models. J Immunotoxicol 5(1): 23-31. 